\title{
Kinetics of Serological Response in Patients with Severe Fever with Thrombocytopenia Syndrome
}

\author{
Sang Hyun Ra ${ }^{1}$, Min Jae Kim ${ }^{1}$, Min-Chul Kim ${ }^{2}$, Se Yoon Park ${ }^{3}$, Seong Yeon Park ${ }^{4}{ }^{\circledR}$, Yong Pil Chong ${ }^{1}{ }^{\circledR}$, \\ Sang-Oh Lee ${ }^{1}$, Sang-Ho Choi ${ }^{1}$, Yang Soo Kim ${ }^{1}$, Keun Hwa Lee ${ }^{5, * \mathbb{D}}$, Sung-Han Kim ${ }^{1}, * \mathbb{C}$ and Sun-Ho Kee ${ }^{6}$ \\ 1 Department of Infectious Diseases, Asan Medical Center, University of Ulsan College of Medicine, \\ Songpa-gu, Seoul 05505, Korea; jesus4274@naver.com (S.H.R.); nahani99@gmail.com (M.J.K.); \\ drchong@amc.seoul.kr (Y.P.C.); soleemd@amc.seoul.kr (S.-O.L.); sangho@amc.seoul.kr (S.-H.C.); \\ yskim@amc.seoul.kr (Y.S.K.) \\ 2 Division of Infectious Diseases, Department of Internal Medicine, Chung-Ang University Hospital, \\ Dongjak-gu, Seoul 06973, Korea; pour-soi@hanmail.net \\ 3 Division of Infectious Diseases, Department of Internal Medicine, Soonchunhyang University College of \\ Medicine, Yongsan-gu, Seoul 04401, Korea; sypark@schmc.ac.kr \\ 4 Department of Infectious Diseases, Dongguk University Ilsan Hospital, Dongguk University College of \\ Medicine, Ilsandong-gu, Goyang-si 10326, Korea; psy99ch@hanmail.net \\ 5 Department of Microbiology, Hanyang University College of Medicine, Seongdong-gu, Seoul 04763, Korea \\ 6 Department of Microbiology, Korea University College of Medicine, Seongbuk-gu, Seoul 02841, Korea; \\ keesh@korea.ac.kr \\ * Correspondence: yomust7@gmail.com (K.H.L.); kimsunghanmd@hotmail.com (S.-H.K.)
}

check for

updates

Citation: Ra, S.H.; Kim, M.J.; Kim, M.-C.; Park, S.Y.; Park, S.Y.; Chong, Y.P.; Lee, S.-O.; Choi, S.-H.; Kim, Y.S.; Lee, K.H.; et al. Kinetics of Serological Response in Patients with Severe Fever with Thrombocytopenia Syndrome. Viruses 2021, 13, 6. https://dx.doi.org/10.3390/ v13010006

Academic Editor: Masayuki Saijo Received: 12 November 2020 Accepted: 16 December 2020 Published: 25 December 2020

Publisher's Note: MDPI stays neutral with regard to jurisdictional claims in published maps and institutional affiliations.

Copyright: () 2020 by the authors. Licensee MDPI, Basel, Switzerland. This article is an open access article distributed under the terms and conditions of the Creative Commons Attribution (CC BY) license (https: / / creativecommons.org / licenses/by/4.0/).

\begin{abstract}
Severe fever with thrombocytopenia syndrome (SFTS) is caused by SFTS virus (SFTSV). We investigated the detailed kinetics of serologic response in patients with SFTS. Twenty-eight patients aged $\geq 18$ years were enrolled between July 2015 and October 2018. SFTS was confirmed by detecting SFTSV RNA in their plasma using reverse transcription polymerase chain reaction. SFTSVspecific IgG and IgM were measured using immunofluorescence assay (IFA) and enzyme-linked immunosorbent assay (ELISA). We found that SFTSV-specific IgG was detected at days 5-9 after symptom onset, and its titer was rising during the course of disease. SFTSV-specific IgM titer peaked at around week 2-3 from symptom onset. The SFTSV-specific seropositive rates for days 5-9, 10-14, 15-19, and 20-24 from symptom onset using IFA and ELISA were $63 \%, 76 \%, 90 \%$, and $100 \%$, and $58 \%, 86 \%, 100 \%$, and $100 \%$, respectively, for IgG, whereas they were $32 \%, 62 \%, 80 \%$, and $100 \%$, and $53 \%, 62 \%, 70 \%$, and $100 \%$, respectively, for IgM. The delayed IgM response could be attributed to the low sensitivity of SFTSV-specific IgM IFA or ELISA and/or impaired immune responses. The IgM test using IFA or ELISA that we used in this study is, therefore, insufficient for the early diagnosis of SFTS.
\end{abstract}

Keywords: severe fever with thrombocytopenia syndrome (SFTS); viral load; immunoglobulin G (IgG); immunoglobulin M (IgM); immunofluorescence assay (IFA); enzyme-linked immunosorbent assay (ELISA)

\section{Introduction}

Severe fever with thrombocytopenia syndrome (SFTS), which is caused by SFTS virus (renamed as Dabie bandavirus) in the genus Bandavirus, family Phenuiviridae, and order Bunyavirales [1], is an emerging endemic zoonosis usually transmitted by ticks, such as Haemaphysalis longicornis [2]. Since its first report in China in 2011 [2], SFTS was subsequently identified in South Korea and Japan in 2012, and reported in 2013 and 2014, respectively $[3,4]$. SFTS has become a significant threat to public health in East Asian countries with a high fatality rate of 16.2-32.6\% [5,6], and effective antiviral therapy for SFTS virus (SFTSV) has not been available [7-9]. 
Previous studies $[10,11]$ have reported that one of the major pathophysiological characteristics that causes high mortality in SFTS is related to cytokine storm. Additionally, other studies $[12,13]$ revealed that the impairment of both innate and adaptive immune responses was associated with disease progression and mortality in SFTS. Song et al. [13] described a defect in serological responses to SFTSV that plays an important role in disease mortality rate, and impairment of both $\mathrm{B}$ and $\mathrm{T}$ cells could contribute to low anti-viral immunity. However, to the best of our knowledge, there is a huge paucity of clinical research data on the pattern of changes in antibody response throughout the course of this disease. We, therefore, investigated the detailed kinetics of anti-SFTSV antibody response in patients with SFTS.

\section{Materials and Methods}

\subsection{Patients and Samples}

Adult patients, aged $\geq 18$ years, with confirmed SFTS, were enrolled at four universityaffiliated hospitals in South Korea during the period of July 2015 to October 2018. The four hospitals were Asan Medical Center, Soonchunhyang University Seoul Hospital, ChungAng University Hospital, and Dongguk University Ilsan Hospital. SFTSV RNA in plasma specimens was confirmed using real-time reverse transcription polymerase chain reaction (RT-PCR). Patients' plasma specimens in ethylenediaminetetraacetic acid (EDTA)-treated vacutainers were obtained during their hospitalization period. Plasma samples were immediately separated from whole blood and frozen at $-80{ }^{\circ} \mathrm{C}$ until further analysis. The study protocol was approved by the Institutional Review Boards of each hospital (2016-127-0748 for Asan Medical Center, 2016-09-001 for Soonchunhyang University Seoul Hospital, 1970-002-376 for Chung-Ang University Hospital, and 2016-01-088 for Dongguk University Ilsan Hospital).

\subsection{Quantification of SFTSV RNA}

SFTSV RNA in plasma specimens was confirmed using RT-PCR as described in our previous study [14]. Briefly, RNA was extracted from the serum specimen using a viral RNA extraction kit (iNtRON Biotechnology, Gyeonggi, South Korea) according to the manufacturer's instructions. To detect SFTSV RNA, the one-step RT-PCR was performed using a DiaStar $2 \times$ OneStep RT-PCR Pre-Mix kit (SolGent, Daejeon, South Korea) with the primers MF3 (5'-GATGAGATGGTCCAT GCTGATTCT-3') and MR2 (5'-CTCATGGGGTGGAATGTCCTCAC-3'), and the following conditions: reverse transcription at $50{ }^{\circ} \mathrm{C}$ for $30 \mathrm{~min}$ and an initial denaturation step at $95^{\circ} \mathrm{C}$ for $15 \mathrm{~min}$, followed by 35 cycles each of denaturation at $95^{\circ} \mathrm{C}$ for $20 \mathrm{~s}$, annealing at $58^{\circ} \mathrm{C}$ for $40 \mathrm{~s}$, extension at $72{ }^{\circ} \mathrm{C}$ for $30 \mathrm{~s}$, and a final extension step of $5 \mathrm{~min}$ at $72{ }^{\circ} \mathrm{C}$.

\subsection{Measurement of Anti-SFTSV IgG and IgM Using IFA}

Serological tests for detecting anti-SFTSV IgG and IgM were performed using the immunofluorescence antibody assay (IFA), as previously described [15]. For IFA, Vero E6 cells infected with SFTSV were incubated in a $5 \% \mathrm{CO}_{2}$ incubator at $37{ }^{\circ} \mathrm{C}$ for five days. Subsequently, cells were harvested, inoculated onto Teflon-coated well slides, and then fixed with acetone. IFA was carried out using a patient's serum as the primary antibody and fluorescein-labeled antihuman IgG or IgM secondary antibodies (Thermo Fisher Scientific, Waltham, MA, USA). Serum specimens were diluted two-fold from 10 up to 2560. The incubation time of a patient's serum for IgM detection was extended to $90 \mathrm{~min}$, whereas $30 \mathrm{~min}$ incubation was performed for IgG detection. A monoclonal anti-SFTSV N antibody (manufactured in our laboratory) was used as the positive control. A titer of 80 was considered positive as applied in the previous study [16].

\subsection{Measurement of Anti-SFTSV IgG and IgM Using ELISA}

The enzyme-linked immunosorbent assays (ELISA) for anti-SFTSV IgM and IgG were performed as previously described [17]. To use the ELISA coating antigens, E. coli-expressed 
recombinant nucleoproteins (NP) were purified. A Nunc-Immuno Plate (Thermo Fisher Scientific, Waltham, MA, USA) was coated with a predetermined optimal quantity of NP (100 ng per well) and incubated overnight at $4{ }^{\circ} \mathrm{C}$. An absorbance reader (Sunrise, Tecan's Magellan $^{\mathrm{TM}}$, Männedorf, Switzerland) was used to measure the absorbance in the ELISA. A sample was considered antibody-positive if it yielded an optical density (OD) above the predetermined cut-off value at $405 \mathrm{~nm}\left(\mathrm{OD}_{405}\right)$. The average $\mathrm{OD}$ values for the negative controls were between 0.18 and 0.24 . The IgM and IgG antibody-positive serum of an SFTS patient, presenting positive results in the immunofluorescence assay (IFA), was used as a positive control $\left(\mathrm{OD}_{405}\right.$ of $\operatorname{IgM}=1.36-1.95$ and $\mathrm{OD}_{405}$ of $\left.\operatorname{IgG}=1.36-1.76\right)$. The anti-SFTSV $\operatorname{IgM}$ and $\operatorname{IgG}$ levels in the specimens obtained from the patients were considered positive if they were higher than the positive control $\left(\mathrm{OD}_{405}=1.36\right)$.

\section{Results}

\subsection{Clinical Characteristics of the Patients}

A total of 28 patients with confirmed SFTS were enrolled in this study. IFA for both $\operatorname{IgG}$ and IgM were performed on all patients during the course of the disease. Among these patients, $14(50 \%)$ were men, and their mean age ( \pm standard deviation) was $61.8( \pm 9.9)$ years. Detailed clinical characteristics of the patients in this study are shown in Table 1.

Table 1. Clinical characteristics of the studied patients.

\begin{tabular}{|c|c|}
\hline Characteristics & No. of Patients $(n=28)$ * \\
\hline Age (years), mean \pm SD & $61.8 \pm 9.9$ \\
\hline \multicolumn{2}{|l|}{ Sex } \\
\hline Male & $14(50)$ \\
\hline Female & $14(50)$ \\
\hline \multicolumn{2}{|l|}{ Season (months) } \\
\hline Spring-Summer (3-8) & $14(50)$ \\
\hline Fall (9-11) & $14(50)$ \\
\hline \multicolumn{2}{|l|}{ Clinical characteristics } \\
\hline Fever & $28(100)$ \\
\hline Tick- or chigger-bite wound & $8(28.6)$ \\
\hline Skin rash & $4(14.3)$ \\
\hline Bleeding & $5(17.9)$ \\
\hline Myalgia & $15(53.6)$ \\
\hline Anorexia/General weakness & $21(75)$ \\
\hline Nausea/Vomiting & $14(50)$ \\
\hline Abdominal pain & $6(21.4)$ \\
\hline Diarrhea & $14(50)$ \\
\hline Cough/Sputum/Dyspnea & $9(32.1)$ \\
\hline Altered mental status & $13(46.4)$ \\
\hline \multicolumn{2}{|l|}{ Underlying diseases } \\
\hline Previously healthy & $12(42.9)$ \\
\hline Diabetes mellitus & $9(32.1)$ \\
\hline Solid tumor & $2(7.1)$ \\
\hline Hematologic malignancy & 0 \\
\hline Chronic liver disease & $1(3.6)$ \\
\hline Chronic kidney disease & 0 \\
\hline Chronic lung disease & $3(10.7)$ \\
\hline Autoimmune disease & $1(3.6)$ \\
\hline Solid organ transplantation & 0 \\
\hline Hematopoietic stem cell transplantation & 0 \\
\hline Immunosuppressant & 0 \\
\hline
\end{tabular}


Table 1. Cont.

\begin{tabular}{|c|c|}
\hline Characteristics & No. of Patients $(n=28)$ * \\
\hline \multicolumn{2}{|l|}{ Clinical courses } \\
\hline General ward admission & $18(64.3)$ \\
\hline ICU admission & $10(35.7)$ \\
\hline In-hospital mortality & $3(10.7)$ \\
\hline \multicolumn{2}{|l|}{ Treatments } \\
\hline Doxycycline & $23(82.1)$ \\
\hline Ribavirin & $14(50)$ \\
\hline Plasma exchange & $19(67.9)$ \\
\hline Convalescent plasma therapy & $2(7.1)$ \\
\hline \multirow[t]{2}{*}{ Self-limiting } & $1(3.6)$ \\
\hline & Median (IQR) \\
\hline \multicolumn{2}{|l|}{ Laboratory findings } \\
\hline White blood cell $(/ \mu \mathrm{L})$ & $1800(1050-2748)$ \\
\hline Neutrophil (\%) & $56(46-69)$ \\
\hline Lymphocyte (\%) & $35(25-48)$ \\
\hline Monocyte (\%) & $6(3-10)$ \\
\hline Hemoglobin (g/dL) & $14.0(12.4-15.0)$ \\
\hline Platelet $\left(\times 10^{3} / \mu \mathrm{L}\right)$ & $60(42-78)$ \\
\hline $\mathrm{BUN}(\mathrm{mg} / \mathrm{dL})$ & $15.0(10.5-23.8)$ \\
\hline Creatinine $(\mathrm{mg} / \mathrm{dL})$ & $0.90(0.62-1.13)$ \\
\hline AST (IU/L) & $204(131-429)$ \\
\hline $\operatorname{ALT}(\mathrm{IU} / \mathrm{L})$ & $95(69-199)$ \\
\hline $\mathrm{CRP}(\mathrm{mg} / \mathrm{dL})$ & $0.4(0.1-0.9)$ \\
\hline $\mathrm{PT} \mathrm{INR}^{+}$ & $1.05(0.99-1.11)$ \\
\hline $\mathrm{aPTT}_{\text {(seconds) }}{ }^{\dagger}$ & $39.9(37.2-46.3)$ \\
\hline \multicolumn{2}{|c|}{$\begin{array}{l}\text { Abbreviations: ALT, alanine aminotransferase; aPTT, activated partial thromboplastin time; AST, aspartate } \\
\text { aminotransferase; CRP, C-reactive protein; ICU, intensive care unit; INR, international normalized ratio; IQR, } \\
\text { interquartile range; PT, prothrombin time; SD, standard deviation. * All clinical characteristics and laboratory data } \\
\text { were obtained when the patients first visited the emergency room or outpatient clinic. Data represent number of } \\
\text { patients }(\%) \text { unless otherwise specified. }{ }^{\dagger} \text { PT INR and aPTT were unavailable in three patients. }\end{array}$} \\
\hline
\end{tabular}

In addition, three patients (10.7\%) died due to aggravated multi-organ failure during the course of this disease. Detailed clinical characteristics and serologic response of these three deceased patients are shown in Supplementary Tables S1 and S2, respectively. Compared to survivors $(n=25)$, only viral load at days $5-9$ from symptom onset was statistically high in the non-survivors group $(p=0.008)$. Other parameters such as age, underlying diseases, and antibody response did not show significant differences between survivors and non-survivors groups.

\subsection{Kinetics of Viremia and Antibody Responses in Patients with SFTS}

Viral load peaked on days 5-9 after symptom onset, and then gradually decreased over the course of disease. Positive IgG titers against SFTSV using both IFA and ELISA were detected on days 5-9 after symptom onset, with a robust antibody response $(\geq 1280)$ for IFA detected around week 3 after symptom onset. Anti-SFTSV IgM for IFA reached its peak level around week 3 after symptom onset. Although, for ELISA, anti-SFTSV IgG and IgM patterns based on disease course were similar, the IgM peak occurred 5 days earlier than for IFA. The detailed kinetic data of viral load and antibody responses are shown in Figure 1 (curved plot) and Figure 2 (scattered plot).

The median times from symptom onset to the last detection of positive viremia to negative viremia, when patients were negative for viral load at discharge, were 14 days (IQR: 10.05-22.50) and 16 days (IQR: 13.00-23.75), respectively. In addition, the median time from the symptom onset to the positive IgG response and the robust IgG antibody response using IFA was 9 days (IQR: 6.00-11.25) and 17 days (IQR: 13.25-20.75), respectively. 
The median time from the symptom onset to the positive IgG response using ELISA was 9 days (IQR: 6.50-11.00).

\subsection{Seropositive Rate of IgG and IgM Based on Time Course of SFTS Disease}

The SFTSV-specific IgG seropositive rates at cut-off values of 80 for IFA and $\mathrm{OD}_{405}$ $=1.36$ for ELISA for day 5-9, 10-14, 15-19, and 20-24 after symptom onset were: $63 \%$, $76 \%, 90 \%$, and $100 \%$, and $58 \%, 86 \%, 100 \%$, and $100 \%$, respectively. The SFTSV-specific IgM positive rates for IFA and ELISA for days 5-9, 10-14, 15-19, and 20-24 after symptom onset were: $32 \%, 62 \%, 80 \%$, and $100 \%$, and $53 \%, 62 \%, 70 \%$, and $100 \%$, respectively (Table 2 ). One $(3.6 \%)$ out of the 28 patients showed positive IgG response (titer cut-off value at 80 for IFA, and $\mathrm{OD}_{405}=1.36$ for ELISA) but was negative for IgM using both IFA and ELISA at day 9 from symptom onset. The detailed data depending on sampling times are shown in Supplemental Figure S1. In the subgroup that excluded the patients $(n=14)$ in whom only early blood samples within 2 weeks from the symptom onset were available, the sensitivities of IgG and IgM IFA were $100 \%$ and $86 \%$, respectively, and the sensitivities of IgG and IgM ELISA were $100 \%$ and $93 \%$, respectively.

Table 2. Seropositive rates of SFTSV-IgG and -IgM based on patients' clinical course of disease.

\begin{tabular}{ccccccc}
\hline \multicolumn{7}{c}{ For IgG * } \\
\hline Days from Symptom Onset & $\mathbf{1 - 4}$ & $\mathbf{5 - 9}$ & $\mathbf{1 0 - 1 4}$ & $\mathbf{1 5 - 1 9}$ & $\mathbf{2 0 - 2 4}$ & $\mathbf{2 5 - 2 9}$ \\
\hline IFA & $1 / 2$ & $12 / 19$ & $16 / 21$ & $9 / 10$ & $9 / 9$ & $3 / 3$ \\
$(\geq 80)$ & $(50 \%)$ & $(63 \%)$ & $(76 \%)$ & $(90 \%)$ & $(100 \%)$ & $(100 \%)$ \\
ELISA & $0 / 2$ & $11 / 19$ & $18 / 21$ & $10 / 10$ & $9 / 9$ & $3 / 3$ \\
$\left(\mathrm{OD}_{405} \geq 1.36\right)$ & $(0)$ & $(58 \%)$ & $(86 \%)$ & $(100 \%)$ & $(100 \%)$ & $(100 \%)$ \\
\hline & \multicolumn{3}{c}{ For IgM * } & & & \\
\hline Days from Symptom Onset & $\mathbf{1 - 4}$ & $\mathbf{5 - 9}$ & $\mathbf{1 0 - 1 4}$ & $\mathbf{1 5 - 1 9}$ & $\mathbf{2 0 - 2 4}$ & $\mathbf{2 5 - 2 9}$ \\
\hline IFA & $0 / 2$ & $6 / 19$ & $13 / 21$ & $8 / 10$ & $9 / 9$ & $2 / 3$ \\
$(\geq 80)$ & $(0)$ & $(32 \%)$ & $(62 \%)$ & $(80 \%)$ & $(100 \%)$ & $(67 \%)$ \\
ELISA & $0 / 2$ & $10 / 19$ & $13 / 21$ & $7 / 10$ & $9 / 9$ & $3 / 3$ \\
$\left(\mathrm{OD}_{405} \geq 1.36\right)$ & $(0)$ & $(53 \%)$ & $(62 \%)$ & $(70 \%)$ & $(100 \%)$ & $(100 \%)$ \\
\hline
\end{tabular}

Abbreviations: ELISA, enzyme-linked immunosorbent assay; IFA, immunofluorescence assay; IgG, immunoglobulin G; IgM, immunoglobulin M; OD, optical density. * Numerator and denominator represent a number of seropositivity and a number of available data, respectively.

A.

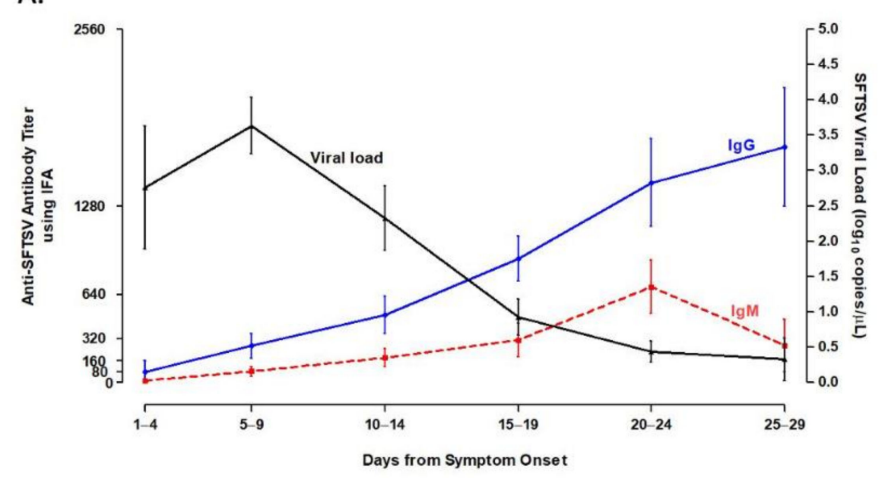

B.

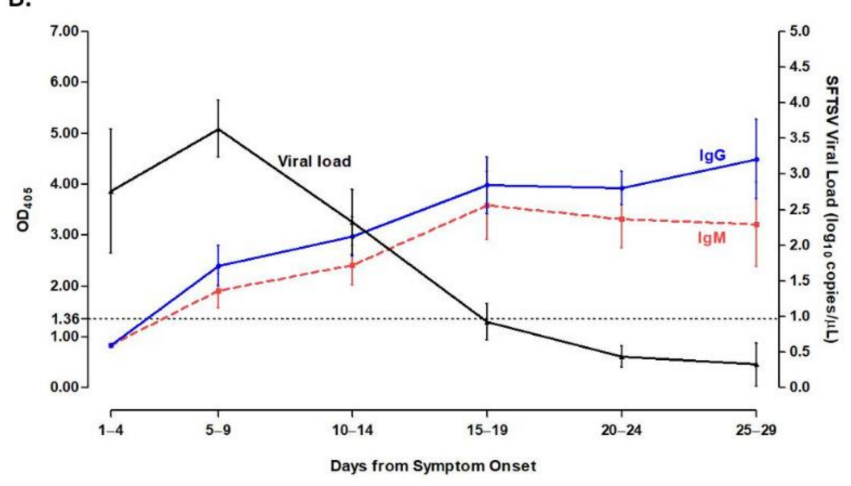

Figure 1. Kinetics of viremia and antibody responses in patients with SFTS. Data are denoted as means with standard error of mean (SEM). Both IgG and IgM were measured using IFA (A) and ELISA (B). 
A.

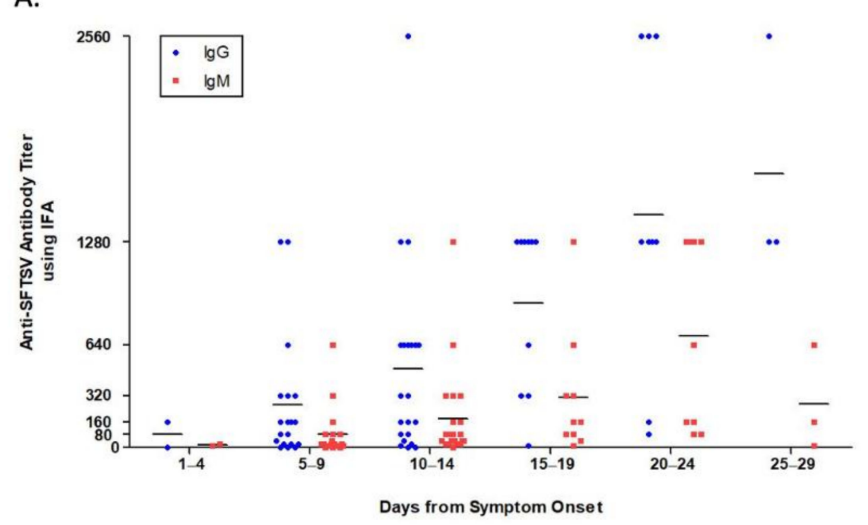

B.

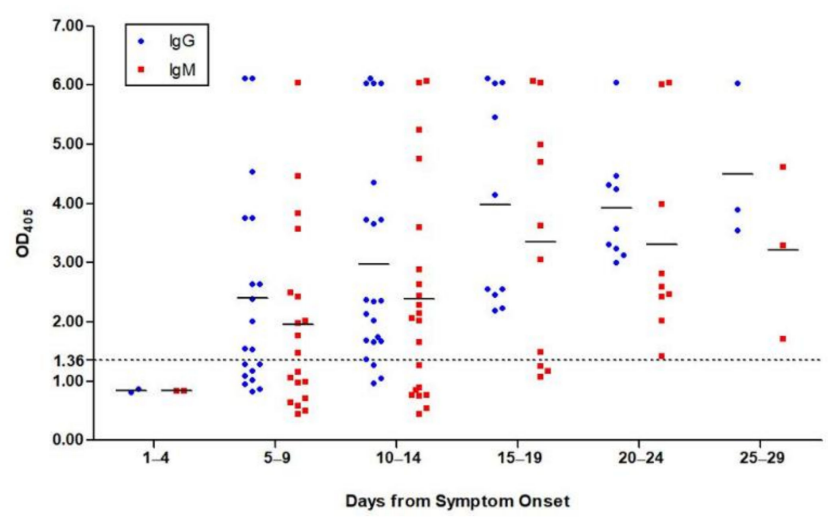

Figure 2. Scattered plot of antibody responses in patients with SFTS. Data are denoted as means. Both IgG and IgM were measured using IFA (A) and ELISA (B).

\section{Discussion}

Since the detection of SFTSV in 2009 in China, SFTS has become a public health threat in East Asian countries. One of the biggest concerns related to SFTS is the high mortality rate due to the lack of effective treatment. Even up to this point, pathogenesis and immune responses of SFTS are still poorly understood.

A prior study [18] suggested that anti-SFTSV IgM levels could be detected at a medium of 9 days, peaking at week 4, and persisted until six months after disease onset; anti-SFTSV IgG could still be detected at a medium of six weeks and peaked at six months. Another study [13] reported that SFTSV NP-specific IgM was detected at an early phase after symptom onset, persisting throughout hospitalization in all recovered patients, with SFTSV NP-specific IgG detected from week 2 after symptom onset. However, our data showed that SFTSV-specific IgM using IFA was detected only at days 15-19 after symptom onset, and peaked at around week 3. However, SFTSV-specific IgM using ELISA was detected at days 5-9 from symptom onset, and peaked at days 15-19. Additionally, SFTSV-specific IgG was detected at days 5-9 after symptom onset, with a robust antibody response $(\geq 1280)$ using IFA observed at around week 3 . Moreover, one of the 28 patients was positive for IgG, but not for IgM, at day 9 from symptom onset. These results indicate that IgM serological tests using IFA or ELISA alone is inadequate for the early diagnosis of SFTS.

Taken together, these results indicate that careful consideration should be given to the issue of delayed IgM response to SFTSV in the course of this disease. It is well known that activated naïve $B$ cells, after infection or immunization, can polarize their surface $\operatorname{IgM}$ and IgD to express IgG, IgA or IgE through immunoglobulin class switching [19]. Therefore, although it is possible that delayed IgM response to SFTSV is associated with the sensitivity of SFTSV-specific IgM IFA, we could not rule out the possibility of SFTSVinduced alterations in host immune response. In particular, one of the aforementioned studies [13] suggested that interleukin (IL)-10 contributes to the impaired B cell immunity by inhibiting germinal center formation and differentiation of dendritic cells. This finding indicates that impaired B cells may affect the immunoreactivity of IgM to SFTS virus. Therefore, in contrast to other studies, our data showed a delayed IgM response compared to that of IgG. However, this finding may be associated with the following attributes of the cohort: a small sample size, experimental challenges due to the sensitivity of SFTSV-specific IgM IFA or ELISA, and/or attenuated adaptive immune response to SFTS. Thus, further in-depth studies with more sensitive serological tests for SFTSV will answer this important phenomenon.

Nevertheless, there were several limitations in our present study. First, most of the sera specimens were collected on 5-19 days from symptom onset (Supplementary Figure S1). For this reason, it was difficult to evaluate the antibody response in the recovery phase of SFTS. Therefore, further well-designed studies with long-term follow-up for SFTS are required. Second, we had a relatively small number of patients $(n=28)$, including only 
three deceased patients with different specimen collection dates. For these reasons, there seems to be no significant difference between the survivor and non-survivor groups. Third, we did not perform any experiment on cell-mediated immune response which could have provided some important highlights on the mechanism of SFTSV infection. Fourth, we determined the cut-off value of OD in ELISA using positive controls rather than standard methods such as the average of negative controls plus three times the standard deviation $($ mean $+3 S D)$ or receiver operator characteristic (ROC) analysis. Thus, the relatively high cut-off value of the ELISA we used might result in the underestimation of the sensitivity of this assay. However, this did not substantially alter our main findings in terms of the results of suboptimal sensitivity of SFTSV-specific IgM IFA during the early course of SFTS patients. Finally, we did not demonstrate that the IFA or ELISA we used were sensitive enough to detect small amount of SFTSV-specific antibodies. Therefore, it is difficult to draw a firm conclusion that the IgM test using IFA or ELISA is insufficient for the early diagnosis of SFTS. Further studies based on more robust designs, focusing on cellular and humoral immune responses against SFTSV, will be of pivotal importance in the quest for developing vaccines and antiviral agents.

In conclusion, our data suggest that SFTSV-specific IgM response was relatively delayed compared to that reported in previous studies. This may be related to the low sensitivity of SFTSV-specific IgM IFA or ELISA, and/or impaired adaptive immune response. Thus, the SFTSV-specific IgM IFA or ELISA that we used in this study are insufficient for the early diagnosis of SFTS, and further robust studies are required to elucidate the humoral and cellular immune responses against SFTSV.

Supplementary Materials: The following are available online at https:/ / www.mdpi.com/1999-491 5/13/1/6/s1, Figure S1: Detailed information about all 28 studied patients' admission, sampling, and discharge and/or deceased times based on days from symptom onset, Table S1: Detailed clinical characteristics of the three deceased patients, Table S2: Viral load and serologic responses of the three deceased patients.

Author Contributions: Conceptualization, S.-H.K. (Sung-Han Kim); methodology, S.H.R., M.J.K., M.-C.K., S.Y.P. (Se Yoon Park), S.Y.P. (Seong Yeon Park), Y.P.C., S.-O.L., S.-H.C., Y.S.K., K.H.L., S.-H.K. (Sung-Han Kim), S.-H.K. (Sun-Ho Kee); software, K.H.L., S.-H.K. (Sung-Han Kim), S.-H.K. (Sun-Ho Kee); supervision, S.-H.K. (Sung-Han Kim); validation, S.H.R., S.-H.K. (Sung-Han Kim); formal analysis, S.H.R., S.-H.K. (Sung-Han Kim); funding acquisition, S.-H.K. (Sung-Han Kim); data curation, K.H.L., S.-H.K. (Sun-Ho Kee); writing-original draft, S.H.R., K.H.L.; writing-review and editing: K.H.L., S.-H.K. (Sung-Han Kim), S.-H.K. (Sun-Ho Kee). All authors have read and agreed to the published version of the manuscript.

Funding: This study was supported by grants from the Government-wide R\&D Fund Project for Infectious Disease Research (GFID), Korea (grant no. HG18C0037) and Korea National Institute of Health (KNIH), Korea (grant no. 2021-ER5304-01).

Data Availability Statement: The data presented in this study are available in this article and Supplementary Material.

Acknowledgments: We thank the participants of this study. We are grateful to Joon Seo Lim for assistance with English editing.

Conflicts of Interest: There are no potential conflicts of interest for any authors.

\section{References}

1. Kuhn, J.H.; Adkins, S.; Alioto, D.; Alkhovsky, S.V.; Amarasinghe, G.K.; Anthony, S.J.; Avšič-Županc, T.; Ayllón, M.A.; Bahl, J.; Balkema-Buschmann, A.; et al. 2020 taxonomic update for phylum Negarnaviricota (Riboviria: Orthornavirae), including the large orders Bunyavirales and Mononegavirales. Arch. Virol. 2020, 165, 3023-3072. [CrossRef] [PubMed]

2. Yu, X.J.; Liang, M.F.; Zhang, S.Y.; Liu, Y.; Li, J.D.; Sun, Y.L.; Zhang, L.; Zhang, Q.F.; Popov, V.L.; Li, C.; et al. Fever with thrombocytopenia associated with a novel bunyavirus in China. N. Engl. J. Med. 2011, 364, 1523-1532. [CrossRef] [PubMed]

3. Kim, K.H.; Yi, J.; Kim, G.; Choi, S.J.; Jun, K.I.; Kim, N.H.; Choe, P.G.; Kim, N.J.; Lee, J.K.; Oh, M.D. Severe fever with thrombocytopenia syndrome, South Korea, 2012. Emerg. Infect. Dis. 2013, 19, 1892-1894. [CrossRef] [PubMed] 
4. Takahashi, T.; Maeda, K.; Suzuki, T.; Ishido, A.; Shigeoka, T.; Tominaga, T.; Kamei, T.; Honda, M.; Ninomiya, D.; Sakai, T.; et al. The first identification and retrospective study of severe fever with thrombocytopenia syndrome in Japan. J. Infect. Dis. 2014, 209, 816-827. [CrossRef] [PubMed]

5. Choi, S.J.; Park, S.W.; Bae, I.G.; Kim, S.H.; Ryu, S.Y.; Kim, H.A.; Jang, H.C.; Hur, J.; Jun, J.B.; Jung, Y.; et al. Severe fever with thrombocytopenia syndrome in South Korea, 2013-2015. PLoS Negl. Trop. Dis. 2016, 10, e0005264. [CrossRef] [PubMed]

6. Li, H.; Lu, Q.B.; Xing, B.; Zhang, S.F.; Liu, K.; Du, J.; Li, X.K.; Cui, N.; Yang, Z.D.; Wang, L.Y.; et al. Epidemiological and clinical features of laboratory-diagnosed severe fever with thrombocytopenia syndrome in China, 2011-2017: A prospective observational study. Lancet Infect. Dis. 2018, 18, 1127-1137. [CrossRef]

7. Kim, U.J.; Kim, D.M.; Ahn, J.H.; Kang, S.J.; Jang, H.C.; Park, K.H.; Jung, S.I. Successful treatment of rapidly progressing severe fever with thrombocytopenia syndrome with neurological complications using intravenous immunoglobulin and corticosteroid. Antivir. Ther. 2016, 21, 637-640. [CrossRef] [PubMed]

8. Oh, W.S.; Yoo, J.R.; Kwon, K.T.; Kim, H.I.; Lee, S.J.; Jun, J.B.; Ryu, S.Y.; Kim, H.A.; Hur, J.; Wi, Y.M.; et al. Effect of early plasma exchange on survival in patients with severe fever with thrombocytopenia syndrome: A multicenter study. Yonsei Med. J. 2017, 58, 867-871. [CrossRef] [PubMed]

9. Park, S.Y.; Choi, W.; Chong, Y.P.; Park, S.W.; Wang, E.B.; Lee, W.J.; Jee, Y.; Kwon, S.W.; Kim, S.H. Use of plasma therapy for severe fever with thrombocytopenia syndrome encephalopathy. Emerg. Infect. Dis. 2016, 22, 1306-1308. [CrossRef] [PubMed]

10. Sun, Y.; Jin, C.; Zhan, F.; Wang, X.; Liang, M.; Zhang, Q.; Ding, S.; Guan, X.; Huo, X.; Li, C.; et al. Host cytokine storm is associated with disease severity of severe fever with thrombocytopenia syndrome. J. Infect. Dis. 2012, 206, 1085-1094. [CrossRef] [PubMed]

11. Saijo, M. Pathophysiology of severe fever with thrombocytopenia syndrome and development of specific antiviral therapy. J. Infect. Chemother. 2018, 24, 773-781. [CrossRef] [PubMed]

12. Song, P.; Zheng, N.; Zhang, L.; Liu, Y.; Chen, T.; Bao, C.; Li, Z.; Yong, W.; Zhang, Y.; Wu, C.; et al. Downregulation of interferon- $\beta$ and inhibition of TLR3 expression are associated with fatal outcome of severe fever with thrombocytopenia syndrome. Sci. Rep. 2017, 7, 6532. [CrossRef] [PubMed]

13. Song, P.; Zheng, N.; Liu, Y.; Tian, C.; Wu, X.; Ma, X.; Chen, D.; Zou, X.; Wang, G.; Wang, H.; et al. Deficient humoral responses and disrupted B-cell immunity are associated with fatal SFTSV infection. Nat. Commun. 2018, 9, 3328. [CrossRef] [PubMed]

14. Ra, S.H.; Kim, J.Y.; Cha, H.H.; Kwon, J.S.; Lee, H.J.; Jeon, N.Y.; Kim, M.J.; Chong, Y.P.; Lee, S.O.; Choi, S.H.; et al. Coinfection of severe fever with thrombocytopenia syndrome and scrub typhus in patients with tick-borne illness. Am. J. Trop. Med. Hyg. 2019, 101, 1259-1262. [CrossRef] [PubMed]

15. Kim, W.Y.; Choi, W.; Park, S.W.; Wang, E.B.; Lee, W.J.; Jee, Y.; Lim, K.S.; Lee, H.J.; Kim, S.M.; Lee, S.O.; et al. Nosocomial transmission of severe fever with thrombocytopenia syndrome in Korea. Clin. Infect. Dis. 2015, 60, 1681-1683. [CrossRef] [PubMed]

16. Lee, H.; Kim, E.J.; Song, J.Y.; Choi, J.S.; Lee, J.Y.; Cho, I.S.; Shin, Y.K. Development and evaluation of a competitive enzyme-linked immunosorbent assay using a monoclonal antibody for diagnosis of severe fever with thrombocytopenia syndrome virus in bovine sera. J. Vet. Sci. 2016, 17, 307-314. [CrossRef] [PubMed]

17. Yoo, J.R.; Heo, S.T.; Park, D.; Kim, H.; Fukuma, A.; Fukushi, S.; Shimojima, M.; Lee, K.H. Family cluster analysis of severe fever with thrombocytopenia syndrome virus infection in Korea. Am. J. Trop. Med. Hyg. 2016, 95, 1351-1357. [CrossRef]

18. Lu, Q.B.; Cui, N.; Hu, J.G.; Chen, W.W.; Xu, W.; Li, H.; Zhang, X.A.; Ly, H.; Liu, W.; Cao, W.C. Characterization of immunological responses in patients with severe fever with thrombocytopenia syndrome: A cohort study in China. Vaccine 2015, 33, 1250-1255. [CrossRef] [PubMed]

19. Stavnezer, J.; Schrader, C.E. IgH chain class switch recombination: Mechanism and regulation. J. Immunol. 2014, 193, 5370-5378. [CrossRef] [PubMed] 